\title{
Designing an interactive multimedia instructional environment: The Civil War Interactive
}

\author{
Ward M. Cates, Lynn A. Fontana and Charles S. White \\ Department of Leadership, Instruction and Technology, Lehigh University, 111 \\ Research Drive, Mountaintop Campus, Bethlehem PA, USA
}

\begin{abstract}
This article describes the rationales behind the design decisions made in creating The Civil War Interactive, an interactive multimedia instructional product based on Ken Burns's film series The Civil War.
\end{abstract}

\section{Introduction}

Ken Burns's film series The Civil War was first aired on the Public Broadcasting System in the United States in the fall of 1990. Its impact was immediate. From the first night, it was the subject of nationwide discussion and its audience grew progressively larger until, by the final evening, the total viewing audience was estimated to be 50 million. Since then, the series has been rebroadcast several times, reaching still more viewers.

In the century and a quarter since the end of the Civil War, the United States has changed dramatically, moving through the Industrial Revolution, the American Civil Rights Movement, the Jet Age, the Space Age, and now into the Information Age. Despite these changes and the intervening years, the American Civil War appears still deeply embedded in the American psyche. It was at once both a unifying and divisive event. In the words of Shelby Foote: 'Before the Civil War, the United States were, after the war, the United States was.' The country therefore gained a sense of unity and indivisibility as a result of the war, "one nation, under God, indivisible, with liberty and justice for all' (Pledge of Allegiance to the Flag of the United States of America). At the same time, a battle between two large regions of the country had been settled by force of arms, producing a 'winner' and a 'loser'. There are few who would question that the Civil War had a powerful effect on both Northern and Southern philosophy, and on American politics in general. The American Civil War is an event of great real and symbolic importance in American history, an event that students need to appreciate fully in order to understand many of the social, political, and economic issues at work in the United States today. 
Unfortunately, students display seriously limited knowledge about the Civil War. In a national survey of history knowledge conducted in 1986 (Ravitch and Finn, 1987), 68\% of American 17-year-old students could not place the war in the correct half century, and only one in four could place Lincoln's presidency in the correct 20-year period. As Ravitch and Finn wrote:

Not even the strongest history students have a secure purchase on the chronological setting of the Civil War ... Yet we would contend that it is impossible to understand American history at all if one lacks any idea of when the Civil War occurred. It is not only the single most traumatic and decisive domestic event since the thirteen colonies won their independence from Britain; it is also the anchoring event of the nineteenth century, the climatic conflict to which other major events led and from which many others resulted. (pp. 49-50)

The results of the 1988 assessment were no more reassuring (NAEP, 1990c). That assessment showed little change from the 1986 findings. Further, it showed that almost half of the students surveyed lacked an understanding of key 'historical terms, texts, and relationships' (p.7). Students demonstrated a tenuous grasp of the inter-relationships among events prior to and subsequent to the Civil War. In short, students did not appear to understand the significance of the war, nor to comprehend the diversity of both its causes and results:

The report of the National Commission on Social Studies in the Schools (1989) suggested principles for teaching aimed at producing greater understanding in American students. Among their recommendations were the following:

Content knowledge from the social studies should not be treated merely as received knowledge to be accepted and memorized, but as the means through which open and vital questions may be explored and confronted. (p.3)

Students must be made aware that just as contemporary events have been shaped by actions taken by people in the past, they themselves have the capacity to shape the future. (p.3)

Learning materials must incorporate a rich mix of written matter, including original sources, literature and expository writing; a variety of audiovisual materials including films, television, and interactive media; a collection of items of material culture including artefacts, photographs, census records and historical maps; and computer programs for writing and analyzing social, economic, and geographic data. Social studies coursework should teach students to evaluate the reliability of all such sources of information and to be aware of the ways in which various media select, shape, and constrain information. (p.4)

Working with funds from the Corporation for Public Broadcasting, The Civil War Interactive Project worked with Ken Burns to design an interactive multimedia instructional product based on Burns's film series. After consulting with our advisory board of noted historians and educators, we established four goals for the project.

Our principal goal was to help learners recognize that the Civil War, like all events in history, was the product of numerous social, political, and economic forces that inexorably influenced the lives of individuals. We hoped to help students learn to recognize the human factor in the equation of history, to understand the importance of inter-relationship among events, 
individuals, groups, ideas, and locations, and to see how a single pivotal event can influence the flow of history from that date onward.

The second goal was to help students comprehend why there is so much disagreement about historical events in general, and about the Givil War in particular, even among extremely well-informed people. In addressing this goal, we hoped to teach students to identify how point-of-view shapes perception and interpretation, and to develop in them the ability to recognize examples of bias, limited competence to judge, fallacious reasoning, and similar critical issues in evaluating primary and secondary sources. We felt that students needed to understand the important role that regional and personal interest play in interpretation, and to learn to spot such interests in materials to which they are exposed. We also hoped to help students come to appreciate how complex the process of historical interpretation is, and to learn to use the tools of historians and other logical thinkers to assist in structuring their own arguments.

Our third goal was to help students and teachers learn to work in hypermedia/multimedia environments, thereby providing them with information-handling skills that they may need in future as they are exposed to more and more sources and types of information. In this way, students and teachers could learn to cope with the demands of new technology and to make the most of the power of that technology. We wanted to equip them with strategies for managing information, to help them learn to distinguish relevant from irrelevant information, and to use that criterion to select appropriate supporting materials from among those available.

The fourth goal for the project was to use the emotional power of film and video to draw students into the inquiry process. We hoped that this would, in turn, lead students to explore primary source materials and develop their inquiry skills. In keeping with this goal, we included in the product additional primary source materials that do not appear in the film series. We also worked carefully to incorporate both implicit and explicit instruction in the application of the inquiry process to historical investigation.

Early in the project we decided that our initial designs and early prototype would utilize level 3 multimedia. This meant storing the video segments from the series on a two-sided 12-inch videodisc, along with selected additional graphics, and using a computer program as the control for access to this disc. In addition, the computer program would supply extra text and graphics, and would provide both instructional organization and support for leamers. Materials stored on the videodisc would be displayed on a separate large classroom monitor connected to the videodisc player while the computer control program, additional text materials, graphs, and animations would be displayed on the computer's monitor.

As we examined the products currently on the market and considered exactly how we wanted our product to operate, we became aware that some educational multimedia products appeared to confuse a visual database with an instructional environment. Products whose principal use is as a visual database or reference work need, primarily, to have a well-organized and logical database structure and a powerful user interface that allows users to manipulate the database in as many ways as might prove useful. The usual assumption is that 'more powerful' users will manipulate the database in more powerful and incisive ways and that 'less powerful' users will utilize the materials in the database in less powerful and more superficial ways. Novice users, almost by definition, will likely be less powerful users. Implicit in the design of most reference works is a belief that users bring understanding to their searches and that this 
understanding then enables them to take advantage of powerful features of the program to extract the desired materials.

In contrast, in an instructional environment, we expect users to be novices. Learners traditionally are expected to develop understandings of the material under study as they study it, not to bring such understandings to the setting as prerequisites. An instructional environment is expected to be supportive, to help novice learners make transitions from non-understanding or naiveté to increasingly sophisticated understandings and conclusions. Classroom teachers often help learners accomplish these transitions through careful structuring of the materials to be presented, through Socratic questioning, and through carefully guided exploration and discovery followed by debriefing sessions in which learners are given a chance to draw conclusions about what they have leamed.

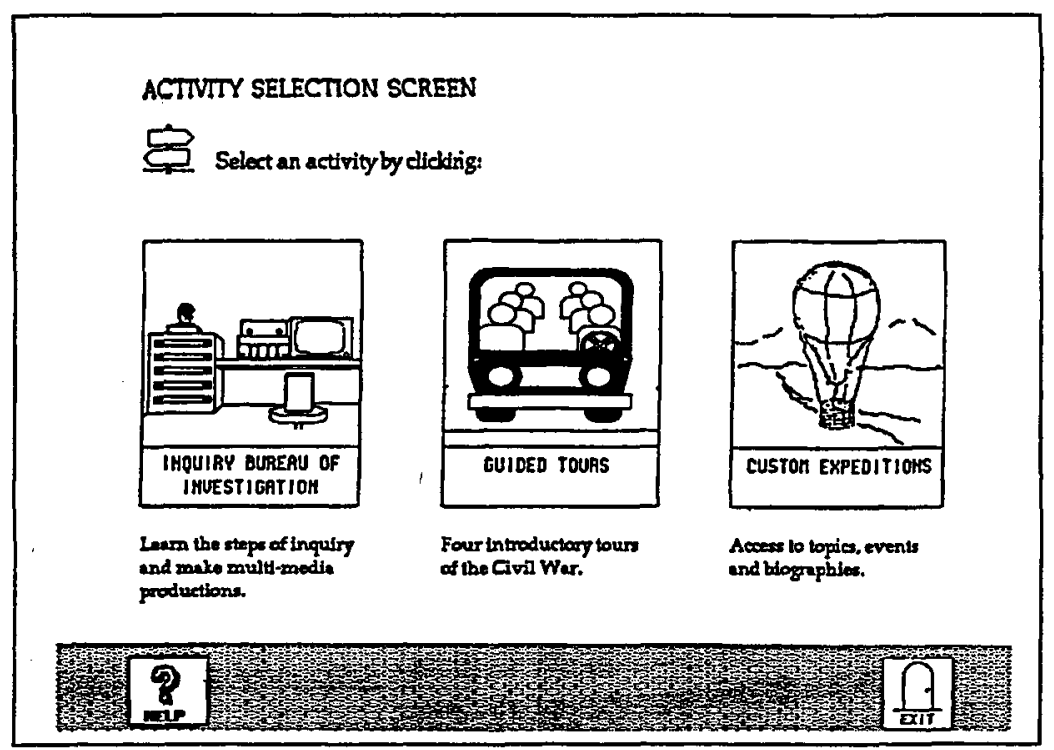

Figure 1: Main activity selection screen

From our discussions with teachers and our own observations, we were aware that students and teachers appeared to use present multimedia products in three main ways: (1) as source materials for student reports; (2) as packaged presentations of content, not unlike regular films or videotapes; and (3) as source materials for individual student or teacher presentations. Present uses did not appear to emphasize use of multimedia materials as a primary form of instruction, however. This fact may be attributable in large part to the earlier discussed failure of many products to provide any actual instruction, viewing themselves, instead, as reference resources. The Civil War Interactive's instructional environment was designed to address the three most frequent uses through its three main strands: Inquiry Bureau of Investigation, Guided Tours, and Custom Expeditions. A major distinction, however, was the product's explicit emphasis on providing direct instruction and instructional support in all three strands. 


\section{Inquiry Bureau of Investigation}

The Inquiry Bureau of Investigation (or IBI) consists of two parts: the Bureau and the Production Console. The Bureau is actually a bureau of drawers, each drawer representing one of the five steps in the inquiry process. Inside each drawer, users find tools and guidance appropriate to that step. Users wishing to proceed systematically step by step through the inquiry process, or learners who are new to the inquiry process, can use the progression through the drawers to help them follow the inquiry process. Users can go directly from an inquiry-process-step drawer to the Production Console to explore the multimedia database or to locate a particular sight they wish to find and can then go back to the Bureau drawer they left. In this way, it is possible for a learner to be supported in the inquiry process while still locating the materials he or she needs to create a multimedia presentation or report. Presentations by noted historians and experienced historical investigators can supply learners with role models to help them learn how to approach an investigation, and presentations addressing the steps in the inquiry process are also available in the Bureau's drawers.

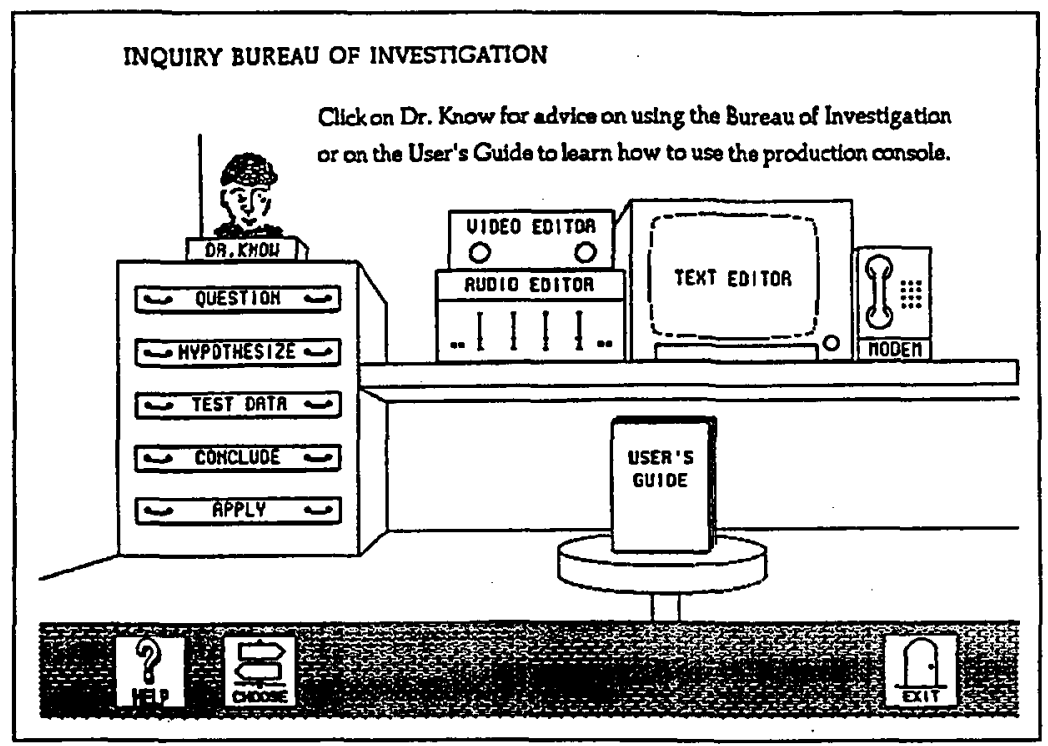

Figure 2: Inquiry Bureau of Investigation

More experienced users can go directly to the Production Console where they may explore the multimedia database freely. They can locate any material in the database using a series of powerful search strategies. Once the desired material is located, they may examine it and decide if it is what they wish to use. If they decide to use it, they can then include it in the presentation or report they are producing. At any point in this production process, users can jump over to the Bureau to get some guidance on how to use the inquiry process to help in their efforts.

The Production Console is designed to enable users to edit video and audio segments, manipulate the database, and import and export digitized versions of materials for use in their multimedia presentations. These latter capabilities should enable users to bring into the system 
such things as files of text, digitized audio, and digitized video, as well as allowing them to get printed copies of documents or graphics in the database or to export their own files for use in an external word processor or graphics program. In addition, the Production Console is designed to allow users to connect with appropriate online information services as such become available.

Users may also use the Production Console to manipulate the materials they collect in their scrapbooks (see below) as they complete guided tours. These materials may then be converted to more formal presentations or reports using the powerful editing capabilities of the Production Console.

\section{Guided tours}

Guided tours focus on presenting learners with carefully structured presentations of a limited scope of the materials available in the multimedia database. Each tour focuses on a specific theme and helps to illustrate that theme through presenting the learner with information drawn from the database. Using the tourist-through-time metaphor, we created tours made up of stops, with each stop containing a limited number of sights. While we intentionally used the s-i-g-h-t spelling, emphasizing the sightseeing aspect of exploration, we also hoped that learners, as they viewed primary documents and saw images of various locales of import during the Civil War, might unconsciously think also of sight's homophonic cousins, cite and site.

In order to help students gain an understanding of the inquiry process, we organized each tour around a thoughtful question. Thoughtful questions help learners to identify why they are about to see what they are. Each thoughtful question is further illuminated by two enabling questions. Enabling questions help to focus the learner's attention on questions whose answers may enable learners to find the answer to a tour's thoughtful question.

Each tour is also designed to help students learn the inquiry process and requires the learner to choose between two available hypotheses. Once a learner selects a hypothesis, all later advice and guidance relates to the testing of that specific hypothesis. Guided tours model the inquiry process, thereby teaching the process implicitly.

We were particularly sensitive to the need to support learners. We were aware that they appeared as a group to lack content knowledge and understanding (NAEP, 1990a,b,c), thinking skills (Beyer, 1988, 1991; Costa, 1985), and an understanding of the persuasive nature of film (Cates, 1990). We felt that The Civil War Interactive needed to address all three of these inadequacies in its instructional environment. We therefore included an advisement feature, Dr. Know. Dr. Know is available from all tour screens and offers three types of advice, which we labelled as $E s, T s$, and $Q s$.

Es consist of advice on how to explore the sights available at a stop. They focus on addressing varied learner intentions, and take a more global view of the content and purpose of sights at the stop.

Ts consist of guidance and advice related to thinking skills. They focus on helping learners understand how individual sights at a stop, or a stop as a whole, relate to a tour's questions and to the hypothesis that the learner selected. 


\section{Thoughtful Question:}

How do people cope when their lives are interrupted by war?

War is a form of national crisis which transforms institutions and the lives of people.

It changes the social, political, èconomic, and cultural life of a nation.

This tour explores the Civil War as a national crisis and investigates how people coped with the changes that it produced.

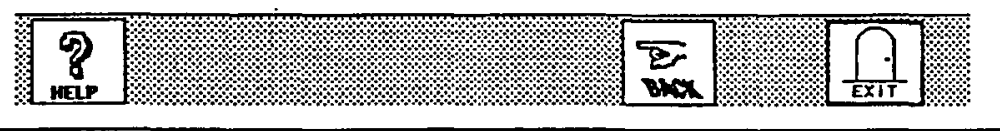

Figure 3: Sample Guided Tour thoughtful question

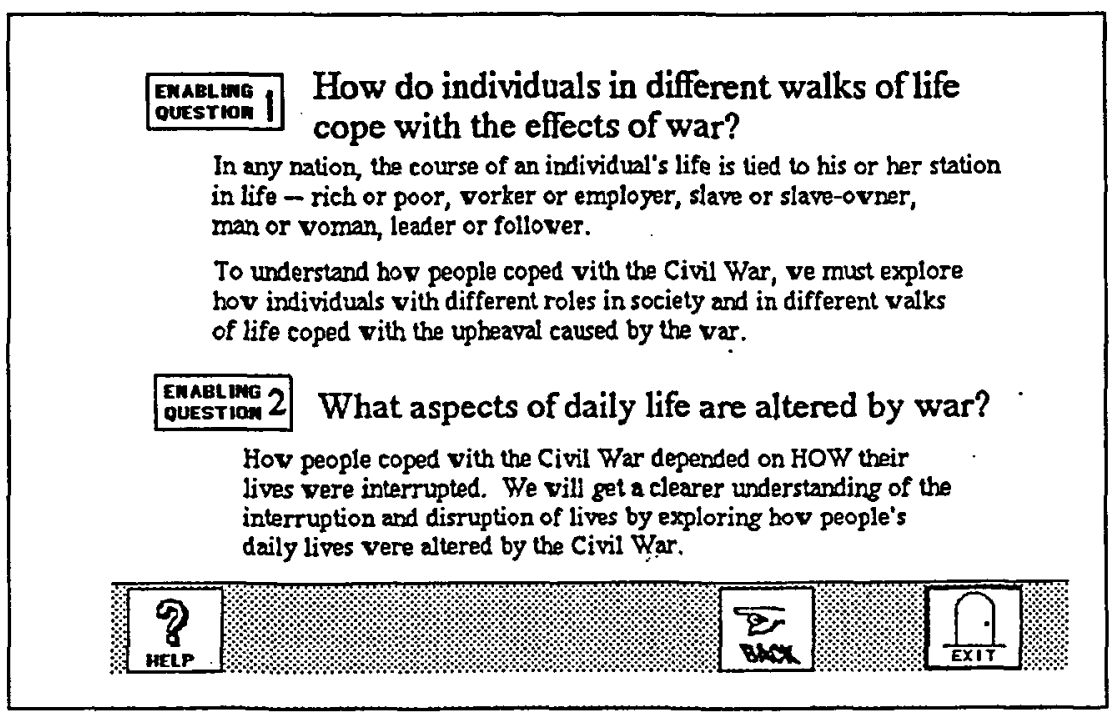

Figure 4: Sample Guided Tour enabling questions

$Q$ s are questions learners might consider while examining the sights at a stop. These questions attempt to do what a talented teacher guiding a leamer in discovery might do: focus student attention on critical aspects of the material under study, point out inconsistencies or dissonant contentions, or pose questions that stimulate deeper thought about key issues.

To help learners recognize the role viewpoint plays in historical interpretation, Dr. Know often plays up differences in viewpoint and opinion. To encourage students to think about and interact with the sights they see, they are encouraged to make entries in an electronic journal 


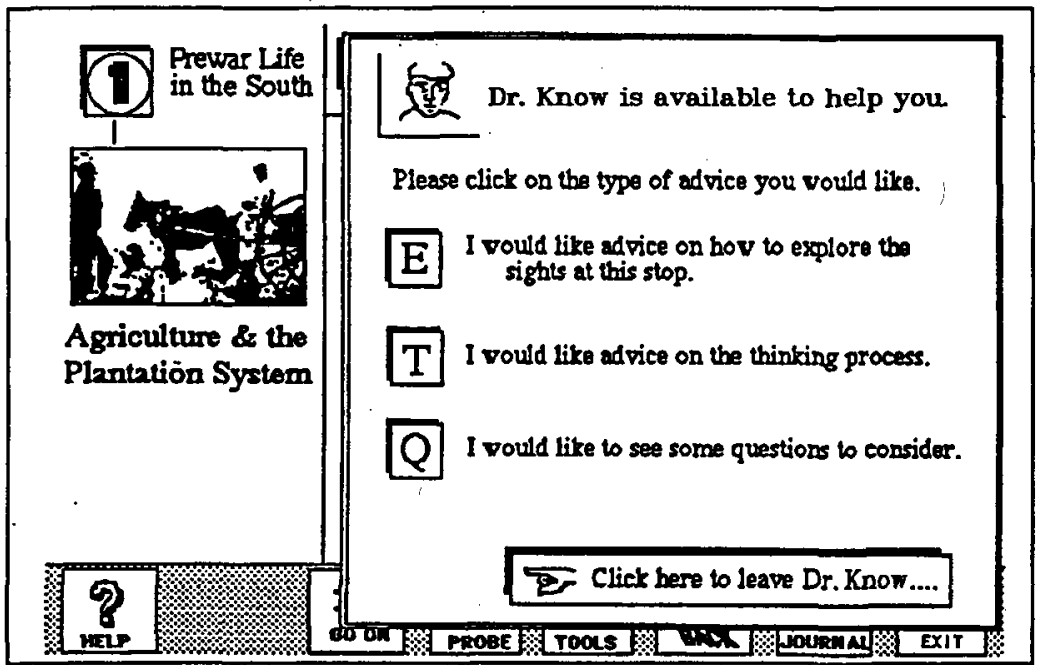

Figure 5: Dr Know's E-T-Q advice selection screen

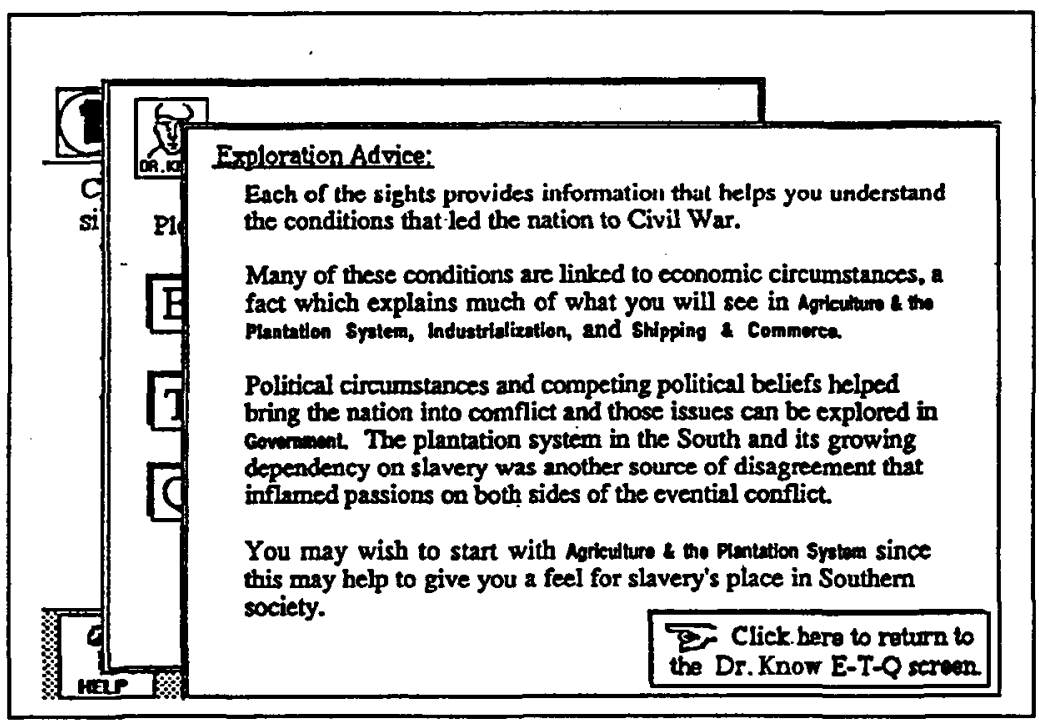

Figure 6: Sample exploration advice

as they go along. In fact, Dr. Know often recommends that they make notations in their journals at particular points in a tour. The electronic journal is part of a larger scrapbook function. In keeping with the tourist and sightseeing metaphor, students may collect souvenirs at stops. Souvenirs may include video or audio clips, copies of documents, graphic illustrations or animation, or any sight the leamer feels is worth saving. All go in the learner's scrapbook. Students can collect materials to take to the Inquiry Bureau of Investigation where 


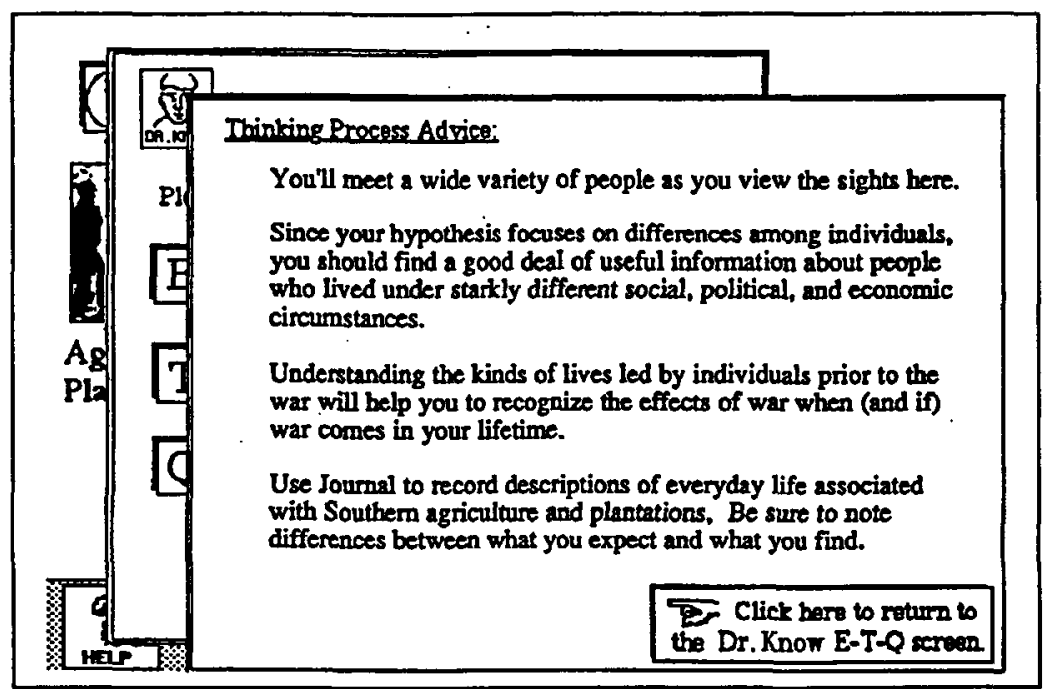

Figure 7: Sample thinking process advice

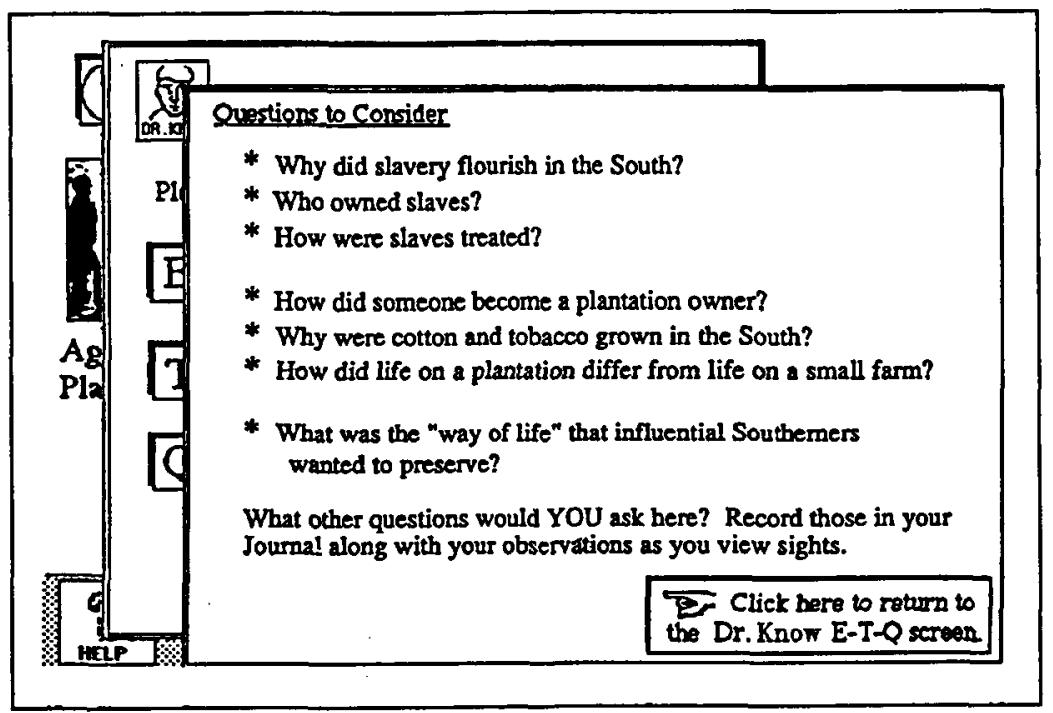

Figure 8: Examples of questions offered by Dr Know

they can use the Production Console to convert any or all of the contents of their scrapbook into formal presentations or reports.

After students have gone to all stops on a tour, they are asked to draw a conclusion about the hypothesis selected earlier. Dr. Know is not available to provide advice at this point, except in terms of explaining what a conclusion is and how one draws a conclusion. Once the student enters a conclusion, Dr. Know becomes available to provide information on what sorts of conclusions might be drawn from the sights seen. 


\section{Custom expeditions}

This portion of The Civil War Interactive allows users to create their own tours to share with others. As was the case in the Inquiry Bureau of Investigation, learners also have access to the search capabilities of the Production Console. In Custom Expeditions, however, users are able to impose formal tour structure on the materials they select by identifying and grouping sights into stops and then grouping stops into tours. Users can also add thoughtful and enabling questions and other properties of guided tours to the custom expeditions they create. In this way, students or teachers may utilize the materials in the database to create their own highly structured and supported instructional presentations. We felt that the ability to build such customized tours using the structure of guided tours (including implicit modelling of the inquiry process) could be of great value in helping teachers make the most of the product, particularly in terms of matching it to local school curricula.

\section{Overall design concerns}

Many interactive multimedia products appear almost too powerful and complex for their intended users. In this case, our intended audience of users consists primarily of 8th and 11th grade US students taking American History courses. A well-documented failing of many multimedia programs is cognitive overload (Oren, 1990; Phye and Andre, 1988). Cognitive overload occurs when the user is overwhelmed by the number or complexity of the options available, and loses a sense of direction and purpose. Often designers refer to this as getting lost in hyperspace. The Civil War Interactive attempts to prevent cognitive overload in a number of ways. It uses no more than eight icons in consistent locations along a control strip at the bottom of the screen, thereby honouring Miller's (1956) guideline on working memory limitations. Each icon is coupled with a descriptive one- or two-word label to help make its function clear. Screens always contain instructions to the user (such as 'Click on any of the items below to ...') and online help is always available from any screen.

To prevent users from losing a sense of where they are in the program, the left-hand portion of guided tour screens is dedicated to a navigation column, which displays in descending sequence the progression of steps that led the user to where he or she is in the program. Pictures in the navigation column illustrate the screens that led to the present screen. Recognizing how easily users can become disoriented in navigating, the product never goes more than four levels down. Clicking on any of the four screen-pictures that may appear in the navigation column returns users to that screen immediately.

Another design concern was the level and nature of learner engagement. We believed that user choices should be meaningful and that users should have some sense of control. To encourage meaningful interaction and a sense of personal control, we included choices at all levels of the program and emphasized the personal nature of inquiry, particularly in terms of selecting tours, choosing a hypothesis, and collecting souvenirs and writing notes in the journal/scrapbook. Recognizing that learner control also means the ability to quit and restart without penalty, we created the map pin feature. The map pin enables users who exit before completing an activity to rejoin the activity at precisely that point when they next restart the program. To encourage learners to assume a sense of responsibility, we employed the language of self-attribution: 'My choice of hypothesis is ...' and 'I would like ...' (Keller and Suzuki, 1988). 


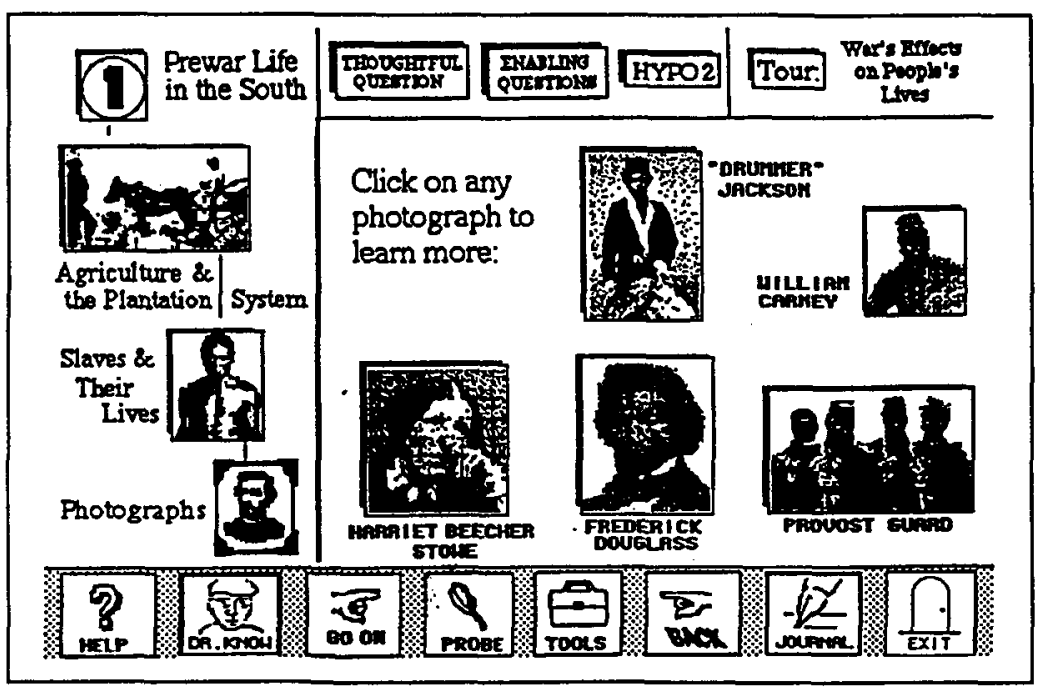

Figure 9: Screen illustrating the navigation column

The Civil War Interactive also emphasizes a sense of control by providing users with devices to help them estimate the scope and length of time required to complete activities. Users can examine brief descriptions of tours (tourbooks) before selecting them; stops often utilize descriptive markers that summarize what the stop covers and time clocks that indicate how long a stop should require to complete if all sights are viewed; and users can skip sights or entire stops as they choose.

We observed that many computer-based educational materials were used by single students in isolation. This often appeared to be the case when they worked with educational multimedia products, particularly those that appear to be designed to be used primarily as references. We hope to encourage a more collaborative and cooperative approach to learning using The Civil War Interactive, an approach in which learners and teachers work together to find the answers to meaningful questions and to see how history, in general, and the Civil War in particular, relate to the present and the future. Accompanying print materials are designed to illustrate a wide range of ways in which to use the product, including one student working alone, small groups of students working independently, one teacher working with a small group, one teacher working with an entire class, and several subject-matter teachers working together with their students.

\section{The future}

The Civil War Interactive project is an on-going one. In December 1990 we completed a 200-page design document specifying how the product was to function. In the first half of 1992 we created a small working prototype of the product to test out its operation and refine its design. Over the next year we demonstrated the prototype, observing reactions and gathering suggestions for changes. The third stage of the project will be the actual development of the commercial version of the product, complete with field tests in a variety of instructional settings and configurations. 


\section{References}

Beyer, B. (1988), Developing a Thinking Skills Program, Boston, Allyn \& Bacon.

Beyer, B. (1991), 'Improving student thinking while learning about the Civil War' in The Civil War Hypermedia Project Design Document, Fairfax VA, Center for Interactive Educational Technology, George Mason University, the Corporation for Public Broadcasting, and Florentine Films, 145-154.

Cates, W. M. (1990). 'Helping students learn to think critically: detecting and analyzing bias in films', The Social Studies, 81, 15-18.

Costa, A. (ed) (1985), Developing Minds: A Resource Book for Teaching Thinking, Washington DC, Association for Supervision and Curriculum Development.

Keller, J. and Suzuki, K. (1988), 'Use of the ARCS motivation model in courseware design' in Jonassen, D. (ed), Instructional Designs for Microcomputer Courseware, Hillsdale NJ, Lawrence Erlbaum, 401-434.

Miller, G. (1956), 'The magical number seven, plus or minus two: some limits on our capacity for processing information', The Psychological Review, 63, 81-97.

National Assessment of Educational Progress (NAEP) (1990a), The Civics Report, Princeton NJ, Educational Testing Service.

National Assessment of Educational Progress (NAEP) (1990b), The Geography Learning of High School Seniors, Princeton NJ, Educational Testing Service.

National Assessment of Educational Progress (NAEP) (1990c), The History Report Card, Princeton NJ, Educational Testing Service.

National Commission on Social Studies in the Schools (1989), Charting a Course: Social Studies for the 21st Century, Washington DC.

Oren, T. (1990), 'Cognitive load in hypermedia: designing for the exploratory learner', in Ambron, S. and Hooper, $\mathrm{K}$ (eds), Learning with Interactive Multimedia: Developing and Using Multimedia Tools in Education, Redmond WA, Microsoft, 126-136.

Phye, G. and Andre, T. (1986), 'Cognition, learning, and education' in Andre, T. and Phye, G. (eds), Cognition and Classroom Learning, San Diego CA, Academic Press, 1-19.

Ravitch, D. and Finn, C. E. Jr. (1987), What Do Our 17-year-olds Know? A Report on the First National Assessment of History and Literature, New York, Harper and Row. 